\title{
Sustainable Rabbit Production under the Global Warming Conditions in Southern Mediterranean Region
}

\author{
Mohamed I. El Sabry ${ }^{1}$, Manal M. Zaki ${ }^{2}$, Fatma A. Elgohary ${ }^{3,}$ and Mostafa M. Helal ${ }^{1 *}$ \\ ${ }^{I}$ Department of Animal Production, Faculty of Agriculture, Cairo University, Giza, Egypt \\ ${ }^{2}$ Department of Veterinary Hygiene and Management, Faculty of Veterinary Medicine, Cairo University, Giza, Egypt \\ ${ }^{3}$ Department of Hygiene and Zoonoses, Faculty of Veterinary Medicine, Mansoura University, Egypt \\ *Corresponding author's Email: Mostafa.helal@agr.cu.edu.eg; (iDORCiD: 0000-0002-8005-9023
}

\begin{abstract}
There is still a wide gap between meat demand and meat production in Egypt. This gap is becoming larger due to the direct and indirect impacts of global warming that negatively influence the grazing area and the performance of livestock. In this context, rabbits are considered as an alternative source for animal-origin meat. In the Southern Mediterranean region, the most obvious problem encountering rabbit production is the hot waves during the summer, especially during the last decades. The narrow thermo-neutral zone of rabbits makes the high temperature hinder the success of commercial production. Different strategies may assist rabbits in coping with heat stress, which are reviewed in the current study, including the improved management practices, development of new breeds, and implementation of different nutritional strategies.
\end{abstract}

Keywords: Global warming, Rabbit production, Southern Mediterranean

\section{INTRODUCTION}

In 2015, the 2030-agenda for sustainable development was under the patronage of the UN. This agenda is considered to be a roadmap to get rid of poverty and hunger across the world through specific actions, including the elimination of and adaptation to global warming effects. Global warming impacts both agricultural and animal production and alters the distribution of different animal species. Animals, particularly rabbits, will experience increasing problems as global warming will alter their physiological and behavioral status over the coming decades.

Domestic rabbits are small herbivores, characterized by a wide range of genetic diversity, as there are more than 30 species and 305 breeds of domestic rabbits worldwide. Rabbit is one of the most recently domesticated animals started in the Iberian Peninsula and the southern region of France. The domesticated rabbits were then transferred to the Mediterranean area and thereafter spread over the world (Carneiro et al., 2011).

Rabbits are highly susceptible to high ambient temperature and face a risk of overheating as their few functional sweat glands do not let them effectively sweat, moreover, their bodies are covered with fur that decreases heat dissipation, and also panting is not efficient for cooling (Weisbroth et al., 2013). The ears are a vital heat-regulating organ in rabbits because they represent about $12 \%$ of the body's surface area and are highly vascular.

\section{Rabbits and global warming}

Global warming negatively affects different agricultural commodities in direct and indirect ways including a decline in rainfall rates, an increase in drought areas, and an increase in the temperatures of many regions worldwide. These abnormal climate changes negatively impact the distribution, productivity, and reproductive performance of all animal species.

The requirements and behavior of rabbits are highly influenced by their geographical origin. Therefore, the geographical origin should be considered when the effect of global warming on commercial rabbit breeds is discussed. Since the rabbit originated in the Mediterranean region, it has been benefited from its geographical area to be adapted to the Mediterranean climate. A great part of this adaptation was derived from the wild rabbit behavior, where it spends the hot hours of the day in its burrow, and goes outside only during the colder early and late hours of the day (El-Raffa, 2004).

Hot climate areas are the obvious and clearest restriction to rabbit production, the susceptibility of this species to heat stress induces a sequence of extreme changes in their biological functions that initiate diminishing of production and reproduction (Smitha et al., 2014). Such adverse effects are stressed during summer, resulting in a restraining breeding period of the rabbits from September to May each year in the Southern Mediterranean region. High ambient 
temperature in the Southern Mediterranean region challenges the animal's ability to maintain energy, water, hormonal, and mineral balances. Nowadays, most of the high-productivity rabbit breeds were developed in Europe due to the advanced breeding programs and optimal growing temperatures. However, the adult body weight of commercial rabbits is reduced by about $20-25 \%$ in hot countries.

Heat stress can indirectly disturb the functions of the immune system by increasing diseases susceptibility, for instance, disturbance of homeostasis by acute infection activates fibroblasts, leukocytes, and endothelial cells (Abdelnour et al., 2020). Therefore, using new disinfectant materials, such as silver nanoparticles may help to control the spread of diseases (Ibrahim et al., 2018). Moreover, the efficacy of vaccination programs may be increased by utilizing some cytokines as a vaccine adjuvant which enhances humoral immunity (El-Sabry et al., 2012).

Accordingly, the problem to produce rabbits on a commercial scale in the Southern Mediterranean regions, such as Egypt, is the susceptibility of rabbits to heat stress. The current study aimed to provide an overview of the negative effects of global warming on rabbits due to its importance as a small livestock species.

\section{Effects of global warming on rabbit performance}

Global warming leads to an annual increase in atmospheric temperature by about $0.07^{\circ} \mathrm{C}$, which in turn causes heat stress on animals, especially in the summer season. Heat stress of animals is defined as stress inflicted by exposure to high ambient temperature and high humidity that prevent them from expressing full genetic potential and/or a physiological status, which could not be regulated by animals to keep their homeostasis and performance at the maximum level. Rabbits can regulate the heat input and output of their bodies using physical, morphological, and behavioral processes to maintain a constant body temperature (Abdelnour et al., 2020).

The thermo-neutral zone of temperature in rabbits is around $18-21^{\circ} \mathrm{C}$. Thus, a relative increase in the ambient temperature, higher than $24-25^{\circ} \mathrm{C}$, induces a reduction in feed intake. However, at $30^{\circ} \mathrm{C}$, rabbits are heat-stressed and feed intake is reduced by about $25 \%$. Different studies on chickens and pigs have presented controversial results concerning the metabolic effects of high ambient temperatures (Lin et al., 2006). Little and incomplete research work are focusing on the effect of acute thermal stress in rabbits (Amici et al., 2000). Furthermore, instabilities in feed digestion, water metabolism, blood metabolites, enzymatic reactions, hormonal secretions, in addition to protein, energy, and mineral imbalances were reported to be interrupted in heat-stressed rabbits (Marco-Jiménez et al., 2017).

Many studies were conducted in different countries on relations between ambient temperature and the rabbit's nutritional requirements. An accurate conception of the diet can reduce the negative effect of hot environments, mainly through an increase of the protein/digestible energy of the diet, but in no case, the composition of the rabbit's feed can alleviate the negative effect of hot temperatures.

In a study conducted by Ahmad Para et al. (2020), heat stress was found to affect the fertility of both bucks and does. When young females were raised until 16 weeks of age, and ovulation rate was measured. A reduction in the number of ova per ovulation was observed, where the number of ova was 7.4 for does raise at $30^{\circ} \mathrm{C}$, compared to 9.2 observed for those raised at $23^{\circ} \mathrm{C}$ (Lebas, 2005). This difference in the number of ova was attributed to the lower live weight of young does raise at $30^{\circ} \mathrm{C}$. Furthermore, high ambient temperatures decreased motility, curvilinear, velocity and metabolic activity of rabbits spermatozoa incubated at $42^{\circ} \mathrm{C}$, compared to $32.5^{\circ} \mathrm{C}$ (Sabés-Alsina et al., 2016).

Litter size and litter weights of does reared in temperate climates are usually higher than those kept under hot climatic conditions as heat stress results in declining energy metabolism and calorigenic hormones which consequently reduces milk yield and so the litter weight gain. The hyperthermic pregnant mothers have inhibited feed intake and so milk yield with depressed thyroid activity and hence metabolic rate leading to decreased embryonic weight at birth. The averages of pre-weaning mortality rates were found to be as high as $71.9 \%$ in summer and $27.3 \%$ in winter (Bassuny, 1999).

The overwhelming negative effects of climate change are extended to encompass welfare. The appropriate surroundings can influence the biological functioning of livestock, including rabbits. When the surrounding environmental conditions change, the rabbits start to change their behavior to cope with the new challenges, which reduce the quality of their lives. Many studies considered temperatures over $24^{\circ} \mathrm{C}$ as above optimal. Starting from $25^{\circ} \mathrm{C}$, rabbits stretch out trying to lose heat by radiation and convection. It was reported that the jumping movements of rabbits completely disappear at $32^{\circ} \mathrm{C}$. At temperatures above $34^{\circ} \mathrm{C}$, rabbits stretch ear pinnae and panting can be noticed (Lebas et al., 1997). Furthermore, there was a report of a reduction in all activities during heat stress periods.

Avoiding undue stress on animals is an important challenge for farmers to avert the adverse consequences of inevitable stress on production. The farmer must advance rabbit husbandry and management, taking into consideration the termed "five freedoms" (McCausland, 2014), including freedom from hunger and thirst, from pain, from an inadequate environment, distress and injuries, from 'fear', and from the inability to express the 'normal' behavioral repertoire. Novice rabbit producers may be unaware of the adverse effects of heat challenges on rabbits as a result of high summer temperatures from May to August. Therefore, the producers must use the available management tools as well as finding new strategies to alleviate heat stress problems. 


\section{Global warming mitigation strategies for sustainable rabbit production \\ Providing good training for the staff}

The performance of rabbits at the different physiological stages depends on the presence of adequate management along with hygiene. Ideal production in hot climates needs crucial requirements, such as highly productive races, probable sheds, comfortable cages, and balanced food to avoid heat stress (El-Raffa, 2004). Most breeders increase rabbit cage density to increase production income and reduce the investment costs in cages and equipment, but this worsens the animal performance (Suatunce Cunuhay et al., 2010). The minimum surface recommended to avoid behavioral disturbances is $625 \mathrm{~cm}^{2} /$ rabbit and less than $40 \mathrm{~kg} / \mathrm{m}^{2}$ at the end of fattening. In tropical conditions, open sheds are the most used facilities, making weather control very difficult, hence induces heat stress during fattening. Therefore, in such conditions, reducing cage density might be more important than in European conditions.

Qualified managerial and technical staff is one of the foremost efficient methods for increasing the production of rabbit farms that can lead to the success of the production system and maximize its revenue. Different cases can prove the importance of qualified and well-trained staff.

\section{Genetic Improvement of local rabbit breeds}

Another possible way to improve the performance of rabbits in hot climate conditions is the genetic improvement for heat tolerance traits. However, in some animals, particularly in rabbits, the generation interval is short and the animal itself is not much expensive. It is important to remark that improving rabbits genetically is a high-cost process for individuals and small farmers, where the breeders need to keep large numbers of animals for a longer time each generation.

Genetic improvement for heat tolerance in rabbits should rely on the local breeds which can be accurately measured by GXE interactions. Although local and native rabbit breeds generally have low productivity, they are welladapted to the local harsh environmental conditions (Helal, 2019; Helal et al., 2021). The advantages of the local breeds in the adaptation to local environmental conditions, including high ambient temperatures, were reported in different animal species, such as chickens, turkeys, ducks, goats, and sheep (Ismoyowati et al., 2019; Canales Vergara et al., 2019; Canales Vergara et al., 2020). Several circumstances need to be changed for the successful improvement of heat tolerance in animals. For instance, the heritability of heat tolerance traits should be high enough to achieve a potential genetic gain, moreover, accurate identification of heat-tolerant animals and the environmental changes must be unchangeable. Thus, heat stress is a complex phenomenon, and selection for heat tolerance is not as easy as selection for growth traits, accordingly, the majority of breeding programs for heat tolerance in rabbits are directed to local breeds (Carabaño et al., 2019). The quickest way for genetic improvement in rabbits is crossbreeding between a local or native breed and a fast-growing breed. Furthermore, many studies investigated the genetic diversity of local breeds (Canales Vergara et al., 2020), as a preliminary step for the conservation of that breeds.

Genetic selection has been successfully employed to improve the rabbit's productive and reproductive traits for a long time either by selecting for one trait or using the multi-traits model. However, the breeding objectives should be modulated to include sustainability and heat tolerance traits. Selection for heat resistance in rabbits is a subject of great importance, but one that has received little research attention. Genetic correlations between body weights and body temperature were found to be positive, however, the genetic correlations between body weights and respiration rate were found to be negative. Local Baladi rabbits have also better resistance to heat stress than New Zealand White regarding the control of body temperatures via their circadian cycles (Finzi et al., 1994). Recently, heat tolerance parameters in rabbits were evaluated, heritability estimates were not significantly different from zero for ear and body temperatures, where it was about 0.12 for respiration rate (Khalil and Al-Homidan, 2014).

\section{Feeding quality improvement}

Another approach can be used to improve the promotion of rabbit production, which is targeting the qualitative and quantitative aspects of the rabbit's feeding. It is necessary to work at a regional scale on possibilities and alternatives of complete feeds supply involving the highest possible proportion of local ingredients, such as Vitamin $\mathrm{C}$ and sodium bicarbonate. The use of Vitamin $\mathrm{C}$ and other antioxidants were recommended to be used as supplements for rabbits during hot periods. Plant sources of Vitamin C are biologically safe for livestock production. Baobab fruit pulp meal can easily be recognized by local farmers and may not have any hazardous effect on the animals and the secondary consumers. The white, powdery pulp is reported to have a high content of Vitamin C (Russo et al., 2019). Polat and El Sabry (2014) found that supplementation of the diet with essential oils can affect feeding behavior. This also can be a suggested solution to enhancing the feed efficacy of rabbits under improper conditions. In addition, the revolution of nanotechnology possibly can play a role in improving the feed efficacy by delivering the nutritional requirements of rabbits in smaller amounts (El-Sabry et al., 2018).

\section{Using some medicinal plants}

Some herbal medicines have been used to alleviate the effects of stressors. In this concern, there are diverse medicinal plants that may be used to reduce the heat stress effects on rabbits. For instance, Lupinus albus L., contained in the dried sweet white lupine seeds, improves livestock production efficiency (van Barneveld, 1999). Lupin also has 
good nutritional quality; alpha-galactoside-free lupin can be used as an excellent dietary source for the preparation of dietetic products.

Trigonella foenum graecum L., found as the dried fenugreek seeds, has a long history of medical uses in traditional medicine and has been used for numerous indications, including labor induction, aiding digestion, and as a general tonic to enhance metabolism and health. Fenugreek is traditionally used to treat diabetes disorders, as preliminary trials suggested possible hypoglycemic and anti-hyperlipidemic properties of oral fenugreek seed powder.

Cassia senna L., loaded in the dried Senna leaves, can be consumed for decreasing the likelihood of adverse effects in the digestive system and relaxing the intestines due to a metabolic effect involving energy production (Nadal et al., 2003). Moreover, it is documented that a hot climate increases insulin sensitivity (Sanz Fernandez et al., 2015) since heat stress increases the level of IGF1 by increasing IGFBP-3 (Xin et al., 2018). The premise is that if any component lowers circulating glucose levels, it indicates that this component improves insulin sensitivity and lowenergy diet utilization. Some essential oils were found to decrease blood sugar and blood pressure, implying that these natural ingredients improve insulin sensitivity.

\section{Some other strategies}

There are different strategies that can be used for decreasing the effect of heat stress on rabbits. Such strategies include providing shade for animals, using cooling systems, drinking cold water. Some other strategies are listed in Table 1. Together with the conventional technique, new applications of nano-materials can be used in house construction e.g. shed isolation and nano-paints to reduce the heat transition from outside to inside the shed (El-Sabry et al., 2018).

Table1. Different methods for providing optimum temperature for rabbits in the Southern Mediterranean region

\begin{tabular}{lll}
\hline Method & Idea & Advantage \\
\hline Fan & $\begin{array}{l}\text { Move air above the cages (not directed to } \\
\text { the rabbits) }\end{array}$ & $\begin{array}{l}\text { Reducing the distress and also expelling } \\
\text { flies }\end{array}$ \\
\hline $\begin{array}{l}\text { Bottles filled with } \\
\text { frozen water }\end{array}$ & $\begin{array}{l}\text { Once your rabbits become familiar with } \\
\text { their bottles, they will lean against them for } \\
\text { relief }\end{array}$ & Cheap and practical option \\
\hline $\begin{array}{l}\text { Mister } \\
\text { pressuring water through nozzles and } \\
\text { blowing mist over the rabbit cages using } \\
\text { fans }\end{array}$ & Efficient in hot dray regions \\
\hline $\begin{array}{l}\text { Evaporative cooling } \\
\text { system }\end{array}$ & $\begin{array}{l}\text { Depend on creating a negative pressure in } \\
\text { the house by using fans that }\end{array}$ & $\begin{array}{l}\text { Lefficient in hot dray regions } \\
\text { can lead to respiratory } \\
\text { health problems }\end{array}$ \\
\hline
\end{tabular}

\section{CONCLUSION}

Global warming and changes in temperature can significantly affect rabbit production. The review of the articles has indicated that rabbits may be bred in almost all tropical zones. However, production performance is unlikely to be as high as temperate climates. Developing new rabbit lines adapted for high temperatures is among the sustainable solutions for rabbit production in hot climates. For small-scale farmers, the temperature control options outlined above are viable, practical, and simple to use. Air conditioning in enclosed spaces is not discussed because it is not a practical choice. Since each farm's management plan for rabbit production will differ, each farm manager must figure out the way that works best for the farm. As a livestock manager, it is critical to reduce stress, which weakens immunity and makes rabbits more vulnerable to sickness. As a farm manager, the mortality in livestock exists, but it should be at its minimum. Combining the previously listed strategies will allow sustainable rabbit production under hot climates.

\section{DECLARATIONS}

\section{Competing interests}

The authors declared that there is no conflict related to this work, which can negatively impact its publication

\section{Authors' contributions}

All authors contributed equally in conceiving the idea and writing the first draft and the revised version.

\section{Ethical considerations}

Ethical issues (including plagiarism, consent to publish, misconduct, double publication and/or submission, and redundancy) have been checked by the authors. 
Abdelnour SA, El-Saadony MT, Saghir SAM, Abd El-Hack ME, Al-Shargi OYA, Al-Gabri N, and Salama A (2020). Mitigating negative impacts of heat stress in growing rabbits via dietary prodigiosin supplementation. Livestock Science, 240: 104220. DOI: https://www.doi.org/10.1016/j.livsci.2020.104220

Ahmad Para I, Ahmad Dar P, Ahmad Malla B, Punetha M, Rautela A, Maqbool I, Mohd A, Ahmad Shah M, Ahmad War Z, and Ishaaq R (2020). Impact of heat stress on the reproduction of farm animals and strategies to ameliorate it. Biological Rhythm Research, 51: 616-632. DOI: https://www.doi.org/10.1080/09291016.2018.1548870

Amici A, Franci O, Mastroiacono P, Merendino N, Nardini M, and Tomassi G (2000). Short term acute heat stress in rabbits: Functional, metabolic and immunological effects. World Rabbit Science, 8: 11-16. Available at: https://riunet.upv.es/handle/10251/10265

Bassuny SM (1999). Performance of doe rabbits and their weanlings as affected by heat stress and their alleviation by nutritional means, under Egyptian conditions. Egyptian Journal of Rabbit Science, 9: 73-89. Available at: https://ejrs.journals.ekb.eg/

Canales Vergara AMC, Landi V, Bermejo JVD, Martínez A, Acosta PC, Barro ÁP, Bigi D, Sponenberg P, Helal M, Banabazi MH et al. (2019). Tracing worldwide turkey genetic diversity using D-loop sequence mitochondrial DNA analysis. Animals, 9: 897812. DOI: https://www.doi.org/10.3390/ani9110897

Canales Vergara AM, Landi V, Delgado Bermejo JV, Martínez AM, Cervantes Acosta P, Pons Barros A, Bigi D, Sponenberg P, Helal M, and Banabazi MH (2020). Design and development of a multiplex microsatellite panel for the genetic characterisation and diversity assessment of domestic turkey. Italian Journal of Animal Science, 19: 392-398. DOI: https://www.doi.org/10.1080/1828051X.2020.1745695

Carabaño MJ, Ramón M, Menéndez-Buxadera A, Molina A, and Díaz C (2019). Selecting for heat tolerance. Animal Frontiers : The Review Magazine of Animal Agriculture, 9: 62-68. DOI: https://www.doi.org/10.1093/af/vfy033

Carneiro M, Afonso S, Geraldes A, Garreau H, Bolet G, Boucher S, Tircazes A, Queney G, Nachman MW, and Ferrand N (2011). The genetic structure of domestic rabbits. Molecular Biology and Evolution, 28: 1801-1816. DOI: https://www.doi.org/10.1093/molbev/msr003

El-Raffa AM (2004). Rabbit production in hot climates. Proceedings of the 8th World Rabbit Congress Puebla, Mexico, pp. $1172-$ 1180. Available at: http://world-rabbit-science.com/WRSA-Proceedings/Congress-2004-Puebla/Papers/FAO-Rabbit-ScienceDev-Countries/S0-El-Raffa.pdf

El-Sabry MIM, Atta AMM, Tzschentke B, Gharib HBA, and Stino FKR (2012). Potential use of Interleukin-2-rich supernatant adjuvant in Fayoumi hens. Archiv fuer Gefluegelkunde, 76: 162-167. Available at: https://www.european-poultryscience.com/Potential-use-of-Interleukin-2-rich-supernatant-adjuvant-in-Fayoumi-henssupa-nameM11-23MK03-FNR-1-aahrefFULLSCRIPTM11-23MK03-FN-1-asup,QUIEPTQyMjA4MzcmTUIEPTE2MTAxNA.html

El-Sabry MI, McMillin KW, and Sabliov CM (2018). Nanotechnology considerations for poultry and livestock production systems-a review. Annals of Animal Science, 18: 319. DOI: https://www.doi.org/10.1515/aoas-2017-0047

Finzi A, Macchioni P, and Kuzminsky G (1994). Circadian cycle of rabbit body temperature in the hot season. Egyptian Journal of Rabbit Science, 8: 471-474. Available at: https://ejrs.journals.ekb.eg/

Helal M, Hany N, Maged M, Abdelaziz M, Osama N, Younan YW, Ismail Y, Abdelrahman R, and Ragab M (2021). Candidate genes for marker-assisted selection for growth, carcass and meat quality traits in rabbits. Animal Biotechnology, pp. 1-20. DOI: https://www.doi.org/10.1080/10495398.2021.1908315

Helal MM (2019). Association between growth hormone receptor gene polymorphism and body weight in growing rabbits. Advances in Animal and Veterinary Sciences, 7: 994-998. DOI: http://www.dx.doi.org/10.17582/journal.aavs/2019/7.11.994.998

Ibrahim FA, Mousafa K, El Sabry M, Badr JM, and Hassan A (2018). Effect of egg disinfection by silver nanoparticles on eggshell microbial load, hatchability and post-hatch performance of quail chicks. International Journal of Poultry Science, 17: $234-242$. DOI: https://www.doi.org/ijps.2018.234.242

Ismoyowati I, Indrasanti D, Mugiyono S, and Pangestu M (2019). Phytogenic compounds do not interfere physiological parameters and growth performances on two Indonesian local breeds of ducks. Veterinary World, 12: 1689-1697. DOI: https://www.doi.org/10.14202/vetworld.2019.1689-1697

Khalil MH, and Al-Homidan AH (2014). Genetic evaluation for growth traits and thermo tolerance parameters in synthesizing program of new rabbits. Animal Biotechnology, 1(7): $1 . \quad$ Available at: https://fagr.stafpu.bu.edu.eg/Animal\%20Production/1101/publications/Maher\%20Hasab\%20El-Nabi\%20Khalil_2014\%20$\% 20$ Genetic\%20evaluation\%20for\%20growth\%20traits\%20and\%20thermo\%20tolerance\%20parameters.pdf

Lebas F (2005). Rabbit production in tropical zones. III International Rabbit Production Symposium, pp. 1-9. Available at: http://www.cuniculture.info/Docs/Documentation/Publi-Lebas/2000-2009/2005-Lebas-Rabbit-production-tropical-zones.pdf

Lebas F, Coudert P, Rouvier R, and de Rochambeau H (1997). The Rabbit: Husbandry, health, and production. Food and Agriculture organization of the United Nations Rome. Available at: http://www.cuniculture.info/Docs/Documentation/Publi-Lebas/19901999/1997-Lebas-\&-al-The-rabbit-Husbandry-health-and-production.pdf

Lin H, Decuypere E, and Buyse J (2006). Acute heat stress induces oxidative stress in broiler chickens. Comparative Biochemistry and Physiology Part A: Molecular and Integrative Physiology, 144: 11-17. DOI: https://www.doi.org/10.1016/j.cbpa.2006.01.032

Marco-Jiménez F, García-Diego FJ, and Vicente JS (2017). Effect of gestational and lactational exposure to heat stress on performance in rabbits. World Rabbit Science, 25: 17. DOI: https://www.doi.org/10.4995/wrs.2017.5728

McCausland C (2014). The Five Freedoms of Animal Welfare are Rights. Journal of Agricultural and Environmental Ethics, 27: 649662. DOI: https://www.doi.org/10.1007/s10806-013-9483-6

Nadal SR, Calore EE, Manzione CR, Puga FR, and Perez NM (2003). Effects of long-term administration of senna occidentalis seeds 
in the large bowel of rats. Pathology Research and Practice, 199: 733-737. DOI: https://www.doi.org/10.1016/j.toxicon.2015.09.042

Polat M, and El Sabry MI (2014). The effects of essential oils dietary supplementation on feeding behavior of sheep under organic animal husbandry. Journal of Animal and Veterinary Advances, 13: 344-349. DOI: https://www.doi.org/10.3923/javaa.2014.344.349

Russo M, Ronci MB, Vilmercati A, Gionfriddo M, Fanali C, Dugo L, Locato V, Mondello L, and de Gara L (2019). African baobab fruit as promising source of procyanidins. European Food Research and Technology, 246: 297-306. DOI: https://www.doi.org/10.1007/s00217-019-03342-9

Sabés-Alsina M, Tallo-Parra O, Mogas MT, Morrell JM, and Lopez-Bejar M (2016). Heat stress has an effect on motility and metabolic activity of rabbit spermatozoa. Animal Reproduction Science, 173: 18-23. DOI: https://www.doi.org/10.1016/j.anireprosci.2016.08.004

Sanz Fernandez MV, Stoakes SK, Abuajamieh M, Seibert JT, Johnson JS, Horst EA, Rhoads RP, and Baumgard LH (2015). Heat stress increases insulin sensitivity in pigs. Physiological Reports, 3: e12478. DOI: https://www.doi.org/10.14814/phy2.12478

Smitha S, Kannan A, and Sabin G (2014). Growth response of New Zealand White rabbits to dietary probiotic and vitamin C under tropical humid climate. Journal of Animal Research, 4: 273-281. DOI: https://www.doi.org/10.5958/2277-940X.2014.00014.X

Suatunce Cunuhay P, Díaz Coronel TG, and García Cruzatty L (2010). Efecto de la densidad de la plantacion en el crecimiento de cuatro especies bosques tropicales. Ciencia y Tecnología, 3: 23. Available at: https://revistas.uteq.edu.ec/index.php/cyt/article/view/87

van Barneveld RJ (1999). Understanding the nutritional chemistry of lupin seed to improve livestock production efficiency. Nutrition Research Reviews, 12: 203-230. DOI: https://www.doi.org/10.1079/095442299108728938

Weisbroth SH, Flatt RE, and Kraus AL (2013). The biology of the laboratory rabbit. Academic press. Elsevier.

Xin H, Zhang X, Sun D, Zhang C, Hao Y, and Gu X (2018). Chronic heat stress increases insulin-like growth factor-1 (IGF-1) but does not affect IGF-binding proteins in growing pigs. Journal of Thermal Biology, 77: 122-130. DOI: https://www.doi.org/10.1016/j.jtherbio.2018.08.008 